\title{
Rheological Properties of Polyethylene-Modified Asphalt Binder
}

\author{
By Khalid A. Ghuzlan* \\ Ghazi G. Al-Khateeb \\ Yazeed Qasem ${ }^{*}$
}

\begin{abstract}
Polyethylene (PE) is the most common type of plastic. In daily life, plastic bags, plastic bottles, and many other PE products are seen everywhere. Significant amount of plastics are not disposed properly and therefore present as waste material in the environment. Using polyethylene as an additive to asphalt binders may be considered a good way to utilize this material. However, modified asphalt binder properties should be investigated. Rheological properties at higher temperatures of asphalt binders modified with PE are investigated in this study. PE was added to asphalt binder at different percentages by volume of asphalt binder. These percentages were: 3, 4, 5, 6, and 7\%. The rheological properties included: the rotational viscosity $(R V)$, asphalt binders complex shear modulus $\left(G^{*}\right)$, and the phase angle $(\delta)$. It was found that the increase of $P E$ to asphalt binder (PE/A) ratio increased the complex shear modulus $\left(G^{*}\right)$ and the rotational viscosity $(R V)$ of asphalt binders. Furthermore, the rutting parameter $\left(G^{*} / \sin \delta\right)$ was improved. However, the $P E / A$ ratio have no significant effect on the phase angle.
\end{abstract}

\section{Introduction}

Plastics are used almost in all aspect in modern life. Polyethylene (PE) is the most popular type of plastic. Millions of metric tons of PE are produced every year worldwide to be used mainly in packaging. PE is durable and degrades very slowly as other plastics. The process of biodegrading of plastics is very slow; and therefore, it remains for a long time in the environment causing pollution and threat to wildlife. In addition, significant amount of plastics are not disposed properly but rather they are left in the environment.

Green industry and recycling waste materials is a global trend nowadays. Therefore, it will be very effective to convert PE bags used in daily life from a pollutant to a useful material such as an asphalt modifier.

Reprocessing of waste plastics by melting has been proven unsuccessful as the process results in thermo-mechanical reductions and losses in their properties (Tzankova et al., 1997).

\footnotetext{
*Associate Professor, Jordan University of Science and Technology, Jordan. ${ }^{\dagger}$ Associate Professor, Jordan University of Science and Technology, Jordan. *Research Assistant.
} 
The addition of waste plastics to asphalt materials has become a feasible option for not only improving the physical properties of asphalt mixtures but also for being a safe method of disposal of the waste material. In this study; the dynamic shear rheometer (DSR) and rotational viscosity (RV) equipment were used to study the rheological properties of polyethylene-modified asphalt binder.

\section{Modified Asphalt Binders}

Pavement represents huge investment that needs to be maintained and kept in a good condition. Repeated traffic loads and environmental factors represent the major deteriorating factors in asphalt pavements. The three major distresses in asphalt pavement are: fatigue cracking, thermal cracking, and rutting. Asphalt technologists keep searching for new or modified materials to improve the asphalt pavement's resistance to these major distresses.

The asphalt binder properties can be improved by using modifiers. The stiffness of hot mix asphalt at high temperature may be decreased by using some modifiers which help in lay down and compaction during construction. Furthermore, rutting may be reduced by using some modifiers that increase the hot mix asphalt stiffness at high service temperatures. Thermal cracking may be controlled through lowering the stiffness and making the relaxation properties faster. As a result the life cycle cost of the pavement will be reduced.

It is possible to achieve asphalt pavement with longer service life and the lower maintenance activities by using asphalt binders with modifiers. However, the initial cost of asphalt binders with modifiers added to it (modified) is higher compared to unmodified binders. Modified asphalt binders typically are more viscous than unmodified asphalt binders, and tend to show improved adhesive bonding to aggregate particles.

Asphalt modifiers may be divided into: crumb rubber, hydrocarbons, polymers (elastomeric and plastomeric), and antistripping agents, fillers, and fibers.

\section{Modification of Asphalt Binder with Polyethylene (PE)}

Polyethylene (PE) is used in making many products in modern life, especially grocery bags, children toys, and shampoo bottles. PE polymer structure is very simple; it consists of carbon atom connected to two hydrogen atoms.

PE is divided into two main categories: low density polyethylene (LDPE) and the high density polyethylene (HDPE). The LDPE consists of carbon atoms attached to a long chain of polyethylene (density between 0.91 and 0.94 ) while the HDPE without branching (density more than 0.94).

HDPE is stronger than LDPE, but at the same time it is more expensive and harder to make than LDPE. LDPE is obtained through polymerization at 
very high pressures and temperatures; on the other hand, HDPE is obtained by polymerization at relatively low temperatures and pressures.

Awwad and Shbeeb (2007) investigated the properties asphalt mixtures with HDPE and LDPE additives using Marshall Mixture design method. The polymers were used in the hot asphalt mixture in two conditions, as ground and whole pieces. It was found that adding PE to asphalt mixtures increased the stability and VMA values compared to asphalt mixtures without PE additive. Modifying asphalt mixtures with HDPE results in enhanced engineering properties compared to asphalt mixtures modified with LDPE. Highest stability for asphalt mixtures obtained at 12\% grinded HDPE. In general, PE modified asphalt mixtures are more rut and fatigue resistant.

Youtcheff et al. (2004) investigated the performance of asphalt binders modified with different materials (polymers). Modifiers included plastomeric and elastomeric polymers like: Ethylene Terpolymer (Elvaloy), Styrene Butadiene Styrene (SBS), Ethylene Vinyl Acetate (EVA), Ethylene Styrene Interpolymer (ESI), Chemically Modified Crumb Rubber Asphalt (CMCRA). they found the stiffness of binders modified with the plastomers dropped off significantly at temperatures above $58^{\circ} \mathrm{C}$, and the $\mathrm{G}^{*} / \mathrm{sin} \delta$ agreed with rutting resistance measurements of the asphalt mixtures obtained using the Repeated Shear at Constant Height (RSCH) test at $50^{\circ} \mathrm{C}$ and the French Permanent Rut Test (PRT) at $70^{\circ} \mathrm{C}$.

Ho et al. (2006) investigated the effect of modifying asphalt binders with recycled polyethylene materials. Asphalt binder was modified with both PE with low molecular weight and recycled LDPE materials. It was found that asphalt binders modified with recycled LDPE materials performed better than those modified with low molecular PE. Othman (2010) added low-density polyethylene (LDPE) to asphalt concrete mixtures and investigated the effect on fracture toughness. LDPE was added to asphalt mixture by total weight of asphalt. Three percentages of $\operatorname{LDPE}(1.5,3$, and $4.5 \%)$ were added to the asphalt binder then used to prepare the asphalt mixture. Fracture toughness was evaluated using the J-integral concept. Results of the study showed that asphalt binders modified with LDPE have higher fracture toughness and enhanced physical properties than unmodified asphalt binders. The highest fracture toughness was obtained for mixtures modified with 4.5\% LDPE. Maharaj (2009) modified the "Trinidad Lake Asphalt (TLA) and Trinidad Petroleum Bitumen (TPB)" with PE and investigated their rheological properties. Three LDPE percentages were used $(0.5,2$ and $3 \%$ of LDPE by weight) to produce TPB-LDPE and TLA-LDPE. Results of this study revealed that, $G^{*}$ value increased with the increase in the LDPE percentage up to 2 to $3 \%$ LDPE (then the $\mathrm{G}^{*}$ values become plateau). Highest phase angle (more viscous) are obtained at $1 \%$ LDPE.

Burger (2001) studied the rheological characteristics of bitumen modified with $3 \%$ by mass SBS. Results of the study showed adding of polymer leads to a binder that performs better under high temperatures/low frequencies (lower values of $\mathrm{G}^{*}$ ) compared to unmodified bitumen. The polymer-modified binders had more elastic response under these conditions. 
Fernandes (2008) used the DSR to study the rheological properties of polymer-modified asphalt binder (using SBS). Adding polymers to asphalt binder reduced thermal susceptibility at paving temperatures (i.e. the phase angle decreased and the $G^{*}$ increased).

\section{Experimental}

\section{Materials}

In this study, a fresh asphalt binder with $60 / 70$ penetration was used. The source of the asphalt binder is Jordan Petroleum Refinery (JPR). The equivalent Performance Grade (PG) for this asphalt binder is PG 64-10. The specific gravity of the asphalt binder was measured using the pycnometer method AASHTO T 228 and found to be 1.014.

Samples of locally available polyethylene in the form of plastic bags were collected. Also samples of linear low density polyethylene (LDPE) in the granular and the powder forms (Figure 1) were obtained from the plastics and paints factories respectively. The supplier of the LDPE was EQUATE, a petrochemical joint venture in Kuwait. Table 1 shows the properties of the LDPE.

Table 1. Properties of LDPE

\begin{tabular}{|c|c|c|c|}
\hline Property & Units & Test Method & Test Result \\
\hline Density & $\mathrm{g} / \mathrm{cm}^{3}$ & ASTM D 1505 & 0.918 \\
\hline Melt Index & $\mathrm{g} / 10 \mathrm{~min}$ & ASTM D 1238 & 1.0 \\
\hline Melting Point & ${ }^{\circ} \mathrm{C}$ & EQUATE & 124 \\
\hline
\end{tabular}

\section{Preparation of Samples}

The PE/A mastics were prepared with the following percentages: 3, 4, 5, 6, and $7 \%$ by volume of asphalt binder. Mechanical mixer was used to prepare the mastics at a mixing temperature range of 145 to $152^{\circ} \mathrm{C}$. Mixing temperature was determined based on the temperature-viscosity relationship (AASHTO T316).

\section{Blending Polyethylene with Asphalt Binder}

Polymers are hetrogeneous with high molecular weights, therefore it is hard to mix such materials and force them to form a two-phase system. Brule (1996) found that if an asphalt binder and a given thermoplastic polymer are mixed, one of the following three results occurs: firstly; the mix is heterogeneous; in this condition, the components of the mix separate, and the mix has none of the characteristics of an asphalt binder. Secondly, the mix is totally homogenous; in this case, the oils in the bitumen dissolve the polymer perfectly and destroy any molecular interaction. The binder is extremely stable, but the modification of asphalt properties with respect to those of the initial asphalt is very slight. Only its viscosity increases; therefore, not the desired result. Thirdly, the mix is micro-heterogeneous and is made up of two distinct 
finely interlocked phases: This is the compatibility sought and gives the bitumen modified properties. In such a system, some of the oily fractions of the asphalt absorbed by the compatible polymer and it therefore swell to form a polymer phase distinct.

Factors affecting blending are: shear rate, blending time and blending temperature. To blend polymer in the asphalt binder it has to disperse in it, this can be achieved through using high shear rate blender (Al-Dubabe,1996).

The blending time shall be kept to the minimum to ensure economical and practical production. Long time blending has negative impact on modified binder rheological properties (Brule et al., 1988).

The molecular weight of the polymer has great effect on the blending temperature. Polymers with high molecular weight require higher temperature. The most complicated and time consuming step was to blend the asphalt binder with polyethylene to achieve a homogeneous mix. As stated above blending of asphalt binders with polymers is not a stable and easy process.

\section{Blending Plastic Bags with Asphalt}

Nowadays, the global trend is toward the green industry and recycling of waste materials. Because PE is durable and degrades very slowly; plastic bags have caused widespread pollution and threats to wildlife.

In this research; there was a great concern of recycling of the waste PE plastic bags. Many trials were conducted to blend the plastic bags with asphalt.

Firstly, the asphalt binder was heated to a temperature of $160-170^{\circ} \mathrm{C}$, and then the required mass (weight) of PE was added in the form of small segments of plastic. The asphalt binder was mixed with PE by a mechanical mixer at $1,300 \mathrm{rpm}$ for 30 minutes while monitoring the temperature, but the final asphalt mix (mastic) was not homogeneous; because plastic segments could not be dispersed within it. After that; different methods were tried to dissolve the plastic before adding it to the asphalt binder by a wide range of volatile chemical solvents such as: Benzene $\left(\mathrm{C}_{6} \mathrm{H}_{6}\right)$, Toluene $\left(\mathrm{C}_{6} \mathrm{H}_{5} \mathrm{CH}_{3}\right)$, Hexene $\left(\mathrm{C}_{6} \mathrm{H}_{12}\right)$, Acetone $\left(\left(\mathrm{CH}_{3}\right)_{2} \mathrm{CO}\right)$, Dichloromethane $\left(\mathrm{CH}_{2} \mathrm{Cl}_{2}\right)$, and Ethyl acetate $\left.\left(\mathrm{C}_{4} \mathrm{H}_{8} \mathrm{O}_{2}\right)\right)$. None of the above solvents dissolved the plastic, as a result the attempts was stopped with the plastic PE. The attention was paid to another form of PE especially the raw PE.

\section{Blending Granular PE with Asphalt}

The granular PE was the second alternative. The desired amount of PE was weighed and the asphalt binder was heated at $160-170^{\circ} \mathrm{C}$, and then $\mathrm{PE}$ was added gradually while mixing. The mixing continued for 15 minutes while controlling the temperature, but the mixture did not show full homogeneity, and when the temperature of the mix decreased, the PE formed a discrete phase. Another procedure to overcome this problem was to melt the PE granules before adding them to the asphalt binder. The PE granules were heated for a prolonged time at a very high temperature (exceeding $200^{\circ} \mathrm{C}$ ), but the PE did not exhibit a clear melting point; it was only changed into a gel, which quickly stiffened into a solid phase when the temperature slightly 
decreased. As a result, the trials to use the granular PE as an asphalt modifier were stopped, and the last available alternative was the PE powder.

\section{Blending PE Powder with Asphalt}

The PE powder was obtained from a local source. The PE was ground to obtain a powder with uniform fine particles. The asphalt binder was heated to a temperature of $160-170^{\circ} \mathrm{C}$ in small containers, and then the PE powder was added gradually with manual gentle mixing. After that, the blend was mixed by the mechanical mixer at 2,600 rpm for 15 minutes. Mixing Temperature was between 160 and $170^{\circ} \mathrm{C}$.

The final asphalt binder mix (mastic) was homogeneous and had a uniform consistency. Finally, the PE powder was adopted as the potential asphalt binder modifier.

\section{Laboratory Testing}

Dynamic Shear Rheometer (DSR) and Rotational Viscometer (RV) were used to determine the rheological and performance-related properties of the modified-asphalt binder. The measured properties included the complex shear modulus $\left(\mathrm{G}^{*}\right)$, the phase angle $(\delta)$ and the rotational viscosity.

\section{Dynamic Shear Rheometer (DSR)}

Asphalt binder is viscoelastic material, i.e. it behaves as elastic and viscous material at the same time. DSR is used to capture this elastic and viscous behavior of the asphalt binder. DSR is used to measure asphalt binder properties at intermediate to high service temperatures. DSR testing temperature is obtained based on the geographical location of the place where this binder will be used.

The output of the DSR testing is the complex shear modulus $\left(\mathrm{G}^{*}\right)$ and phase angle $(\delta)$. The complex shear modulus $\left(\mathrm{G}^{*}\right)$ is defined as the ratio of maximum applied shear stress to the maximum applied resulted shear strain which under test conditions is caused by the oscillating plates of the DSR.

Elastic portion of the asphalt binder is measured through the phase lag or phase angle $(\delta)$. No time difference between shear stress and shear strain indicates a completely elastic material (zero phase angle). A completely viscous material would have a phase difference or angle of $90^{\circ}$. Therefore, a phase angle between $0^{\circ}$ and $90^{\circ}$ indicates a viscoelastic condition of the material. The elastic portion of the complex shear modulus is defined as the storage shear modulus $\left(\mathrm{G}^{*} \cos \delta\right)$, whereas the viscous portion is defined as the loss shear modulus $\left(\mathrm{G}^{*} \sin \delta\right)$.

Thin asphalt binder sample is used in the DSR test, where the test sample is fixed between two plates. The shearing force is obtained through the oscillation $(1.59 \mathrm{~Hz}$ or $10 \mathrm{radians} / \mathrm{sec})$ of the upper plate with the lower plate begin fixed. Superpave specifications insures acceptable level of fatigue cracking and rutting resistance of asphalt binders through using the DSR test 
output namely the $\mathrm{G}^{*}$ and $\delta$. Rutting is expected to occur at the early age of the pavement. Therefore, fresh and short term aged asphalt binder is used in the DSR test to predict rutting. On the other hand, fatigue cracking is expected to occur in the pavement at the long term of service life. Therefore, aged binder (long term aging obtained using the pressure aging vessel) is used in the DSR test. The Superpave specification states a minimum value of rutting parameter $\left(\mathrm{G}^{*} / \mathrm{sin} \delta\right.$ of $1.0 \mathrm{kPa}$ for fresh binders and $2.2 \mathrm{kPa}$ for RTFO (short term) aged binders. This can be explained in such a way, that stiffer binders (higher $\mathrm{G}^{*}$ values) have better rutting resistance and more elastic binders (lower phase angle values) are more rut resistance, since the pavement recover back its deformation after the loading. Asphalt binders would have high resistance for fatigue cracking if it is elastic (lower values of phase angles) and if it is not too stiff (lower values of $\mathrm{G}^{*}$ values). Therefore, Superpave specification specifies a maximum value of the fatigue parameter $\left(\mathrm{G}^{*} \sin \delta\right.$ of $5,000 \mathrm{kPa}$ for the long term aged asphalt binder (PAV condition), since it is desirable to have this parameter as low as possible. Unaged or short term aged asphalt binder are tested at high test temperature as stated in Superpave specifications. Testing samples are with $1 \mathrm{~mm}$ thickness and $25 \mathrm{~mm}$ diameter.

The asphalt sample (or PE/A mastics) was heated with care, stirring when possible, until it reaches the point it is fluid enough to pour into a silicon mold, and then allowed to cool until it become solid enough to remove the asphalt from the mold. The asphalt disk (sample) was then placed between the fixed plate and the oscillating spindle of the DSR. After about ten minutes, which allowed the sample's test temperature to equilibrate, AASHTO T315 standard method was used to conduct the DSR test.

In this study, the DSR was used to test fresh asphalt binder and PE/A mastics having percentages of: $3,4,5,6$, and $7 \%$ by volume of asphalt binder. Four testing temperatures were used $\left(58,64,70\right.$, and $\left.76^{\circ} \mathrm{C}\right)$ while the loading frequency was set at $10 \mathrm{rad} / \mathrm{s}(1.59 \mathrm{~Hz})$.

\section{Rotational Viscosity $(R V)$}

The rotational viscosity characterizes the asphalt binder for workability during pumping and mixing. The RV test was conducted following the test procedures described in the AASHTO standard test method, AASHTO T316. The asphalt binder sample was poured into the RV test samples and placed into the RV container at a temperature of $135^{\circ} \mathrm{C}\left(275^{\circ} \mathrm{F}\right)$. The spindle is submerged into the asphalt binder sample and starts to rotate at $20 \mathrm{rpm}$ rotational speed. The torque required to reach this speed is used to calculate the rotational viscosity.

The RV apparatus provided the rotational viscosity in (cP or mPa.s). Five readings were recorded at 1-minute interval. The fresh asphalt binder and the $\mathrm{PE} / \mathrm{A}$ mastics with percentages of $3,4,5,6$, and $7 \%$ by volume of asphalt binder were tested.

AASHTO MP1 requires a maximum viscosity limit of 3 Pa.s $=3,000$ $\mathrm{mPa} . \mathrm{s}=3,000 \mathrm{cP}$ (centi-Poise) when tested at $135^{\circ} \mathrm{C}$. Asphalt binder should be workable during pumping and other plant operations, i.e. it should be with low 
viscosity (less than $3 \mathrm{~Pa} . \mathrm{s}$ at $135^{\circ} \mathrm{C}$ ) Asphalt binders with high stiffness are desirable to resist rutting, however, the rotational viscosity at $135^{\circ} \mathrm{C}$ should not exceed specific limit (3 Pa.s) to avoid cracking.

\section{Results and Discussion}

DSR and RV tests were performed on both the original asphalt binder (without additive) and the PE-modified asphalt binder. Results of DSR and RV testing on the two conditions were compared. Rheological properties of the modified and unmodified asphalt binders were compared. Full report of this data is shown in Qasem (2011).

\section{Dynamic Shear Rheometer (DSR)}

The DSR tests were conducted at high temperatures $58,64,70$, and $76^{\circ} \mathrm{C}$. The complex shear modulus and the phase angle were obtained from the DSR tests.

\section{Behavior of Original Asphalt Binder}

The stiffness of the original asphalt binder $\left(\mathrm{G}^{*}\right)$ decreased with the increase in temperature, while the phase angle values increased. i.e., the asphalt binder's viscous portion increased over the elastic portion.

\section{Effect of Polyethylene Modification}

There was an obvious effect of polyethylene on asphalt binder. Adding the PE to asphalt binder increased its stiffness and decreased the phase angle. In other words, the elastic behavior of PE modified asphalt binder was enhanced.

By increasing the polyethylene content, the $\mathrm{G}^{*}$ value increased as shown in Figure 2. The highest $\mathrm{G}^{*}$ value was achieved at $7 \% \mathrm{PE}$ content. The value of $\mathrm{G}^{*}$ for the PE-modified asphalt binder at all percentages was always greater than the value of $G^{*}$ for the original (unmodified) asphalt binder. This indicates that the stiffness of the PE-modified asphalt binder was higher and therefore it would be more resistant to rutting (permanent deformation). 
Figure 1. Linear Low Density Polyethylene (LLDPE)

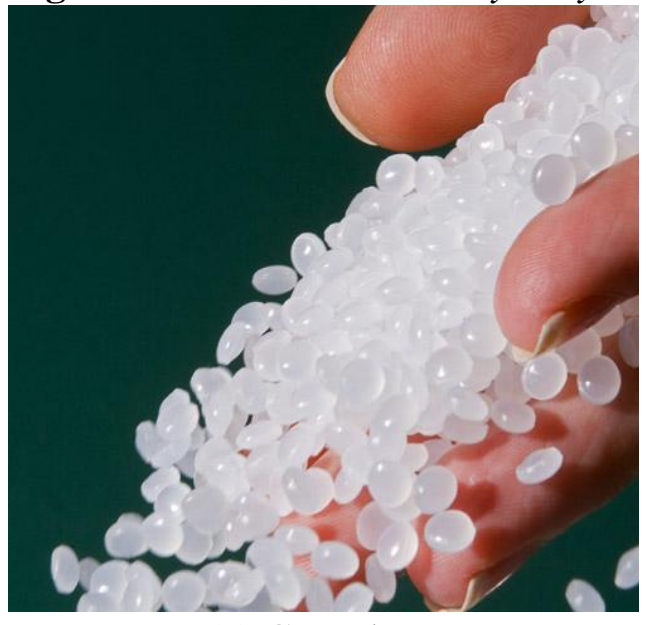

(a) Granular.

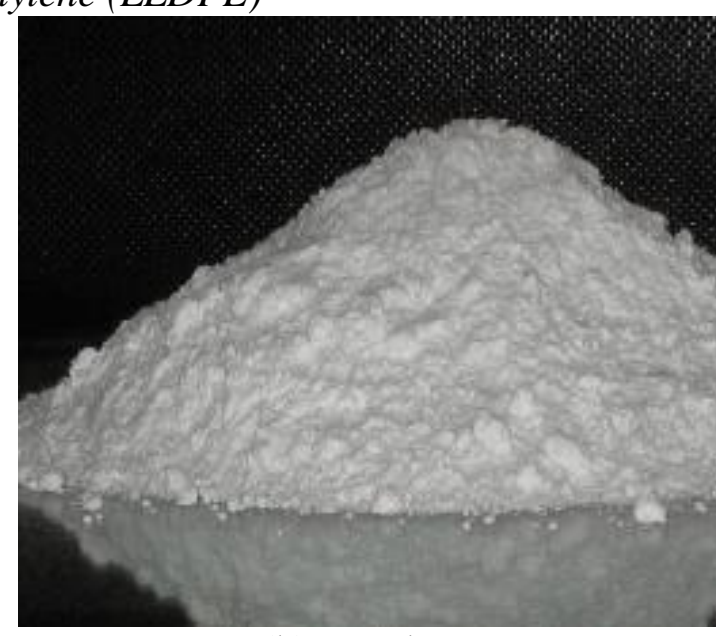

(b) Powder.

Exponential function fits this relation the best. The coefficient of correlation $\left(\mathrm{r}^{2}\right)$ was high $(0.97)$ at all temperatures as shown in Figure 2. This means that the relation between the $\mathrm{G}^{*}$ values and PE content in the asphalt binder is exponential. Figure 3 indicate that the phase angle $(\delta)$ is decreasing with adding polyethylene to asphalt binder. In other words, the elastic portion of the asphalt binder's $G^{*}$ value increased indicating that the asphalt would be more capable of recovering its original shape after being subjected to a load. At the same PE content, the phase angle $(\delta)$ increased by increasing the temperature of testing; suggesting that the asphalt binder would be more viscous.

Figure 2. $G^{*}$ Values for Different PE Percentages at Different Temperatures

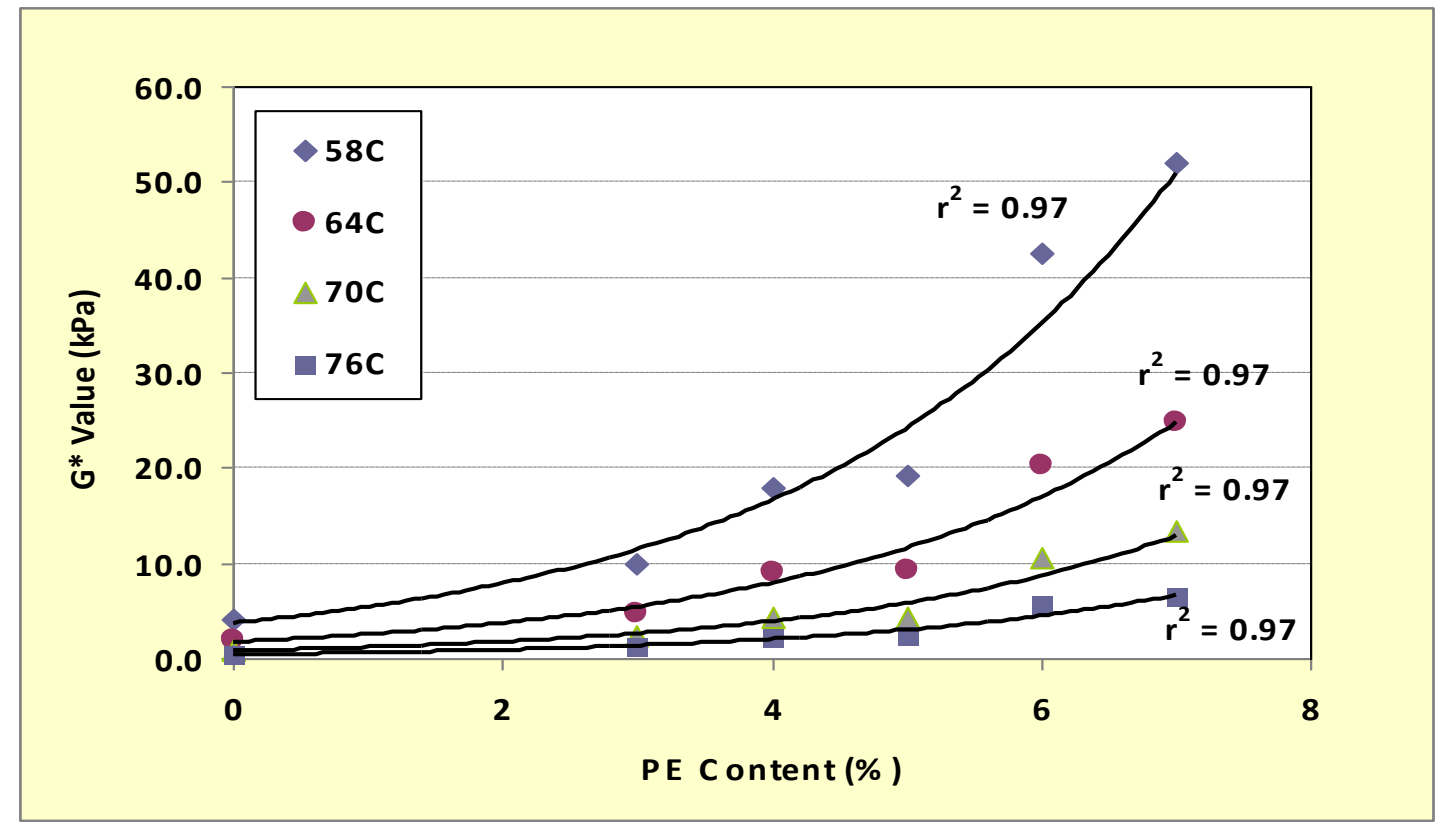


Vol. 2, No. 2 Ghuzlan et al.: Rheological Properties of Polyethylene-Modified...

A polynomial function of a $2^{\text {nd }}$ degree was used to fit the data. The coefficient of correlation $\left(\mathrm{r}^{2}\right)$ was high as shown in Figure 3.

Figure 3. $\delta$ Values for Different PE Percentages at Different Temperatures

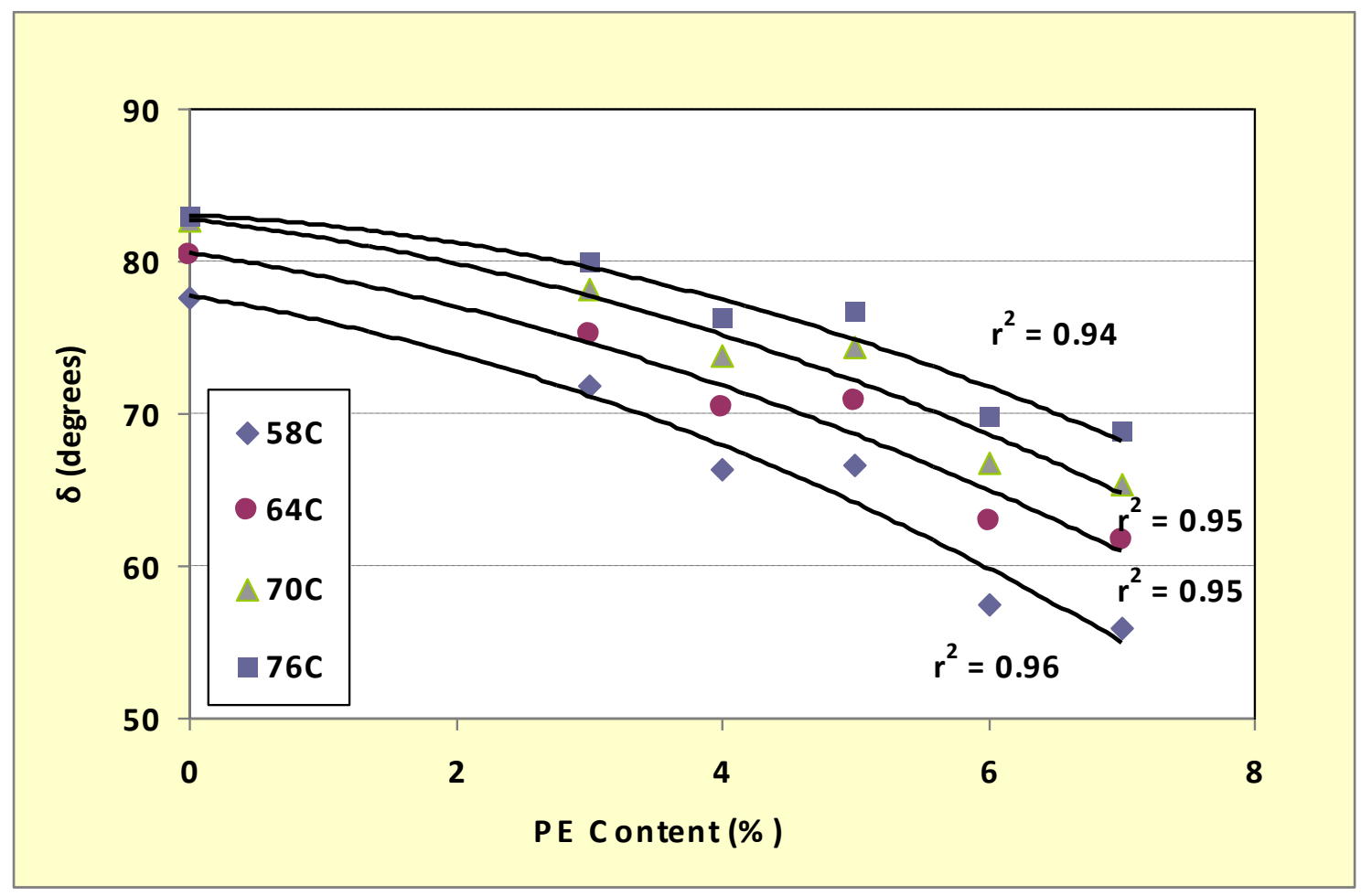

$\mathrm{G}^{*} / \sin \delta$ is the rutting parameter and in general rutting occurs during the early (to mid) of the pavement life. Therefore, Superpave sets a minimum value for rutting parameter; $\mathrm{G}^{*} / \sin \delta$ of $1.00 \mathrm{kPa}$ and $2.2 \mathrm{kPa}$ for the fresh asphalt binder and RTFO-aged asphalt binder, respectively.

The original asphalt binder failed to meet the specifications for the Superpave rutting parameter $\left(\mathrm{G}^{*} / \sin \delta\right)$ at temperatures of $70^{\circ} \mathrm{C}$ and more. On the other hand, all the PE-modified asphalt binders satisfied the Superpave specifications for this parameter at all temperatures: $58,64,70$, and $76^{\circ} \mathrm{C}$. By increasing the temperature, the $\mathrm{G}^{*} / \mathrm{sin} \delta$ value decreased. However, none of the tested PE-modified asphalt binders provided a $\mathrm{G}^{*} / \sin \delta$ value below the minimum Superpave specification of $1.0 \mathrm{kPa}$. As a result of the PE modification, the rutting resistance of the asphalt binder was significantly improved.

Figure 4 shows that by increasing the PE content, the $\mathrm{G}^{*} / \sin \delta$ value increased. The data in this figure was fitted using an exponential function with high coefficient of correlation $\left(r^{2}=0.97,0.97,0.96\right.$, and 0.97 at temperatures: $58,64,70$, and $76^{\circ} \mathrm{C}$, respectively). 
Figure 4. $G^{*} / \sin \delta$ Values for Different PE Percentages at Different Temperatures

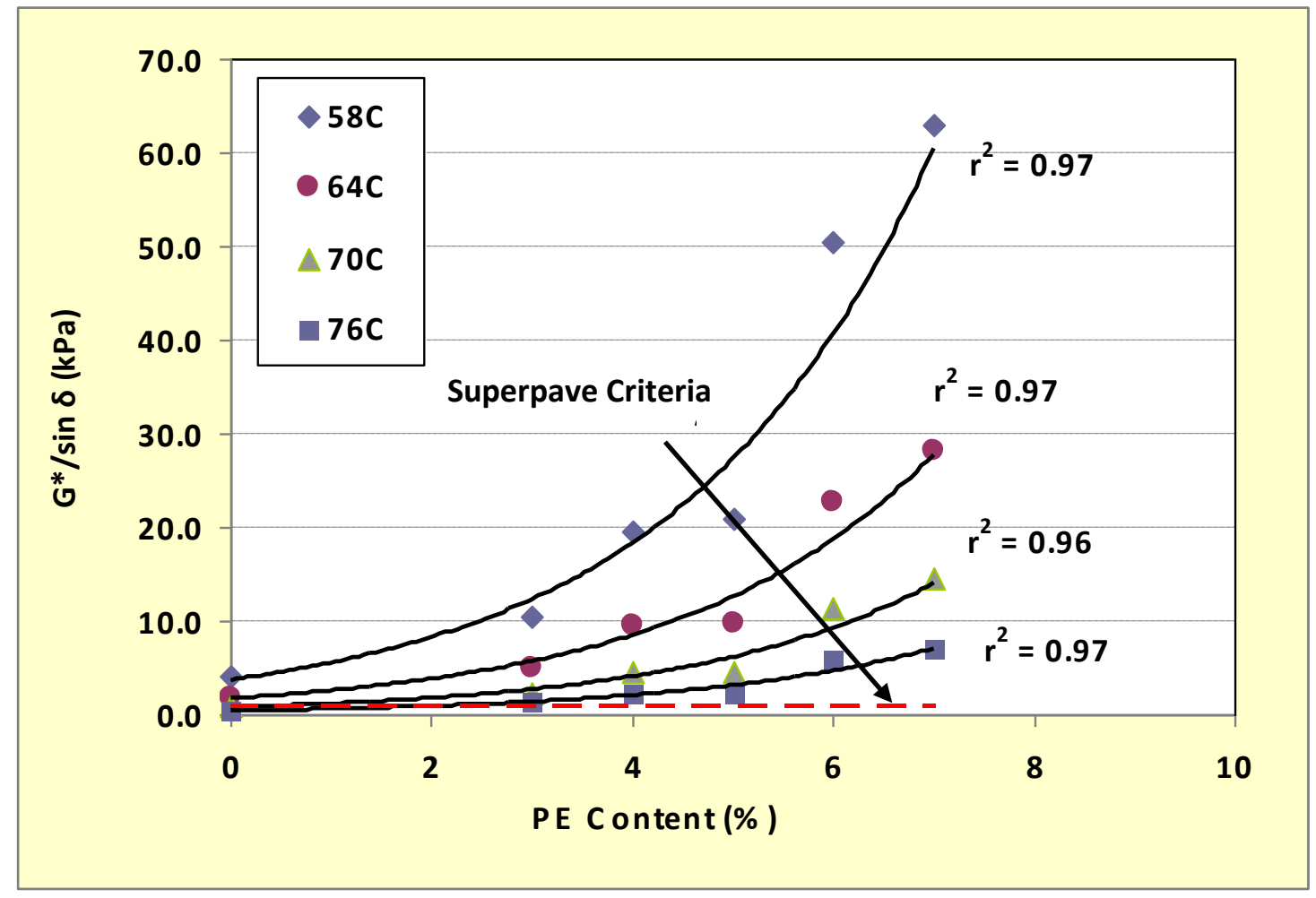

In conclusion, it was obvious that the polyethylene modification had a positive effect on the stiffness and the elastic behavior as both were enhanced.

\section{Rotational Viscosity $(R V)$}

The PE content was plotted with the rotational viscosity as shown in Figure 5. The data was fitted using an exponential function with high coefficient of correlation $\left(\mathrm{r}^{2}=0.99\right)$. The addition of polyethylene had a significant effect on the rotational viscosity of the asphalt as shown in this figure. By increasing the PE content, the RV of the asphalt increased rapidly. According to the laboratory test results, a polyethylene content of $5 \%$ or more was not preferred because of the associated high rotational viscosity values; the asphalt mixes (mastics) at these percentages were not workable. Also, from Figure 5, at $7 \%$ PE content, the PE-modified asphalt binder's rotational viscosity exceeded the Superpave criteria (maximum of 3,000 cP); the RV was $3,658 \mathrm{cP}$. 
Figure 5. $R V$ Values at $135^{\circ} \mathrm{C}$ for Different PE Percentages

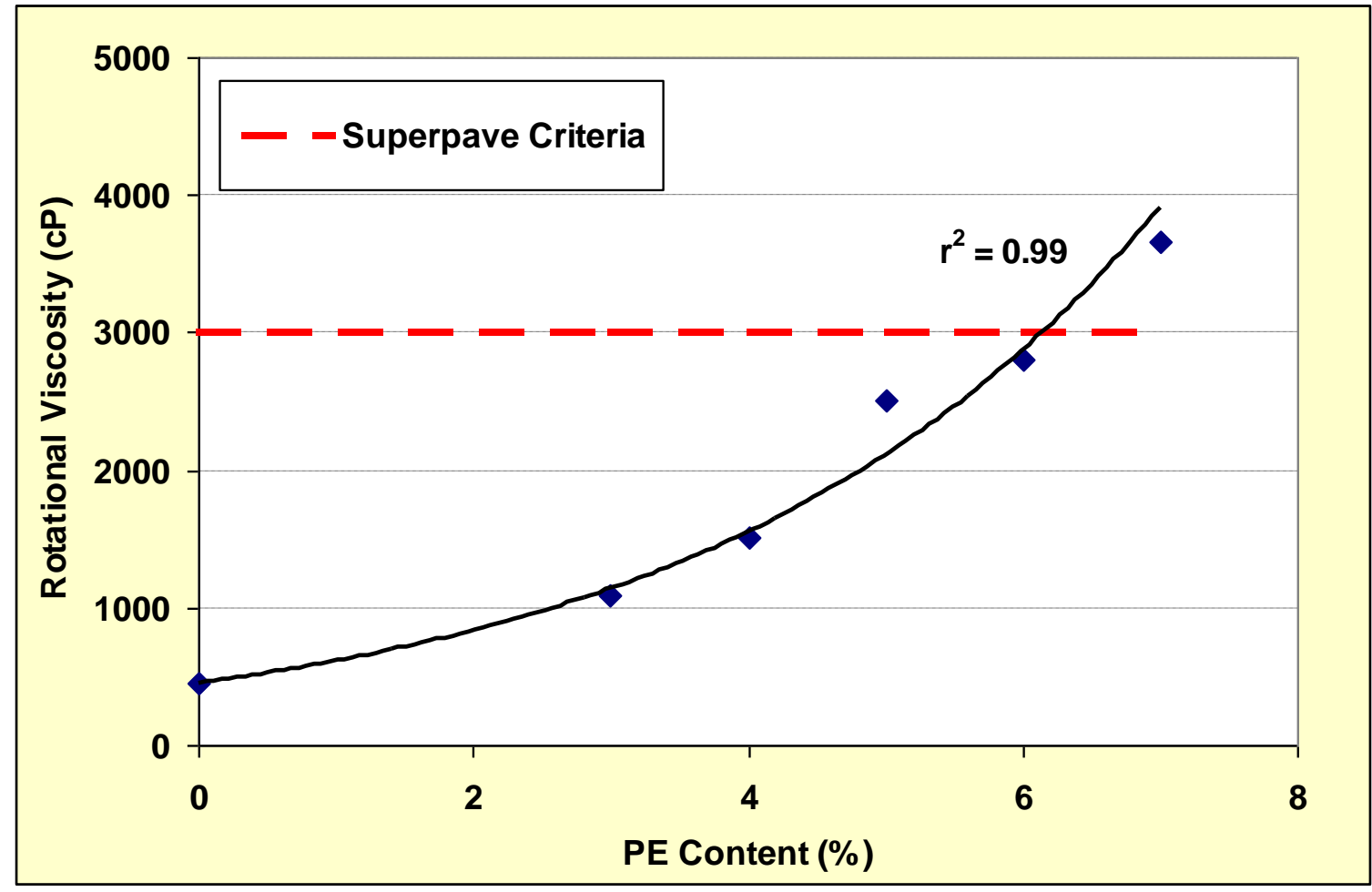

\section{Conclusions}

Based on the DSR and RV testing of both original and PE modified asphalt binder it was concluded the following:

1. The stiffness of the asphalt binder significantly increased with the addition of PE to the asphalt binder. The exponential function fits the best the relationship between the PE content and $\mathrm{G}^{*}$ value. This relation was found to be with high coefficient of correlation $\left(r^{2}\right)$.

2. The addition of PE to the asphalt binder improved the elasticity of the asphalt binder significantly. This could be demonstrated by the decrease in the phase angle $(\delta)$ value.

3. The increase in the PE content resulted in an increase in the value of the rutting parameter $\left(\mathrm{G}^{*} / \sin \delta\right)$; the value of $\mathrm{G}^{*} / \sin \delta$ for the PE-modified asphalt binder at the different PE percentages met the Superpave specifications at high temperatures. As a result, the rutting resistance of the asphalt binder was significantly improved.

4. The increase in the PE content resulted in an increase of the rotational viscosity of the asphalt binder. This increase was exponential, which indicated that the rate of change (increase) in the rotational viscosity with PE percentage was rapid. 
5. The exponential function was found to be the best fit for the relationships between the PE content and each of $\mathrm{G}^{*}, \delta, \mathrm{G}^{*} / \sin \delta$, and RV. This relation was found to be with high coefficient of correlation $\left(r^{2}\right)$ at all temperatures.

6. A PE content of $6 \%$ or more was not applicable because of the high rotational viscosity values. In other words, the PE-modified asphalt binders at these percentages were unworkable due to the high viscosity.

7. A PE content of $3 \%$ could be suggested to be the optimum content. At this content, the rutting resistance was improved such that the $G^{*} / \sin \delta$ met the Superpave specifications for the high performance grade at a maximum temperature of $76^{\circ} \mathrm{C}$. In addition, at this content, the rotational viscosity of the asphalt binder increased by more than $200 \%$ but within a workable limit.

\section{Recommendation}

The authors of this study recommend that further research be conducted to evaluate the effect of aging on PE-modified asphalt binders, the effect of PE on the fatigue behaviour of the asphalt binder, and use the Bending Beam Rheometer (BBR) to study the low temperature cracking.

\section{References}

Al-Dubabe, I. A., "Polymer Modification of Arab Asphalt to Suit Gulf Countries", Performance Requirements". Ph. D. Thesis Dissertation in Civil Engineering, King Fahd University of Petroleum and Minerals, Dhahran, Saudi Arabia, June 1996.

American Association of State Highway and Transportation Officials (AASHTO), AASHTO Standards, AASHTO T228 "Standard Method of Test for Specific Gravity of Semi-Solid Bituminous Materials", 2006.

American Association of State Highway and Transportation Officials (AASHTO), AASHTO Standards, AASHTO T315 "Standard Method of Test for Determining the Rheological Properties of Asphalt Binder Using a Dynamic Shear Rheometer (DSR)", 2008.

American Association of State Highway and Transportation Officials (AASHTO), AASHTO Standards, AASHTO T316, "Standard Method of Test for Viscosity Determination of Asphalt Binder Using Rotational Viscometer, January 2006.

American Association of State Highway and Transportation Officials (AASHTO), AASHTO Standards, AASHTO MP1 "Standard Specification for Performance Graded Asphalt Binder", 1998.

Awwad, M. and Shbeeb, L., "The Use of Polyethylene in Hot Asphalt Mixtures", American Journal of Applied Sciences, Vol. 4, No. 6, 2007.

Brûlé, B., "Polymer-Modified Asphalt Cements Used in the Road Construction Industry: Basic Principles", Journal of the Transportation Research Board (TRB), Transportation Research Record, No. 1535, National Research Council, 
Vol. 2, No. 2 Ghuzlan et al.: Rheological Properties of Polyethylene-Modified...

Washington, D.C. 1996, pp. 48-53.

Brûlé, B., Brion, Y., and Tanguy, A., "Paving Asphalt Polymer Blends: Relationships Between Composition", Structure and Properties. Journal of the Association of Asphalt Paving Technologists (AAPT), Vol. 57, 1988.

Burger, A. F., Van de Ven, M. F. C., Muller, J., and Jenkins, K. J., "Rheology of Polymer Modified Bitumen: A Comparative Study of Three Binders and Three Binder/Filler Systems", $20^{\text {th }}$ South African Transport Conference, South Africa, July 2001.

Fernandes, M., Forte, M., and Leite, L., "Rheological Evaluation of Polymer-Modified Asphalt Binders". Materials Research, Vol. 11, No. 3, 2008, pp. 381-386.

Ho, S., Church, R., Klassen, K., Law, B., MacLeod, D., and Zanzotto, L., "Study of Recycled Polyethylene Materials as Asphalt Modifiers", Canadian Journal of Civil Engineering, Vol. 33, 2006, pp. 1-26.

Maharaj, R., Balgobin, A., and Singh-Ackbarali, D., "The Influence of Polyethylene on the Rheological Properties of Trinidad Lake Asphalt and Trinidad Petroleum Bitumen”, Asian Journal of Materials Science, Vol. 1, Issue 2, 2009, pp 36-44.

Othman, A. "Effect of Low-Density Polyethylene on Fracture Toughness of Asphalt Concrete Mixtures", Journal of Materials in Civil Engineering, Vol. 22, Issue 10, 2010, pp. 951-967.

Qasem, Yazeed. 2011. Rheological Properties of Polyethylene Modified Asphalt Binder. Graduation Project at the Civil Engineering Department, Jordan University of Science \& Technology, Irbid - Jordan.

Tzankova, D. N., Jilov, N., and La Maintain, F. P., "Recycling of Plastics from Packaging", Polymer Degradation Stability, Vol. 57, 1997, pp. 191-203.

Youtcheff, J., Stuart, K., Al-Khateeb, G., and Shenoy, A., "Understanding the Performance of Polymer Modified Binders", Proceedings of the $3^{\text {rd }}$ Eurasphalt \& Eurobitume Congress (EEC), Papers Technical Sessions 5-8, Vol. 2, Vienna, Austria, May 12-14, 2004, pp. BookII-2268-2278. 